\title{
Behavior of Hybrid CRRP-Concrete-Steel Double Skin Tubular Column under Axial Load
}

\author{
Hanaa A. Ali , Wissam D. Salman \\ Department of Civil Engineering,College of Engineering, University of Diyala \\ eng.hanaaabdullbaset1993@gmail.com,dr_wissam80@yahoo.com .
}

\begin{abstract}
Hybrid double skin tubular members (DSTMs) are composite section of three material FRP tube outside, steel tube inside and concrete sandwiches in between. The current study investigated the behavior of fourteen circular DSTCs under axial load. Every specimen is average of a pair of samples, the key parameters are the layers of outer carbon FRP tube, the compressive strength of concrete and the types of columns include (DSTC) and concrete filled FRP tube (CFFT). The test results show that the concrete has effected constrained between two tubes, that's leads to increases strength and ductility of column, the most effective parameters has the number of layers of outer FRP tube the stress-strain relationship shows high ductile behavior of under compression test and the CFFT is superior in ultimate load compared with DSTC.
\end{abstract}

Keywords: Double skin tubular columns, Concrete filled FRP tube, Carbon fiber reinforced polymer tube.

Paper History:(Received:23-5-2019;Accepted:26-6-2019)

\section{Introduction}

Fiber reinforced polymer (FRP) composites are using in wide application in engineering construction to achieve high performance member, such as concrete filled fiber tube and excessive research on CFFT leads to proposed a new hybrid double skin tubular column consist of outer FRP tube-concrete- steel tube $[1,2,3]$, to achieve advantages of these materials in one member, like; increase strength of columns as concrete is confine by two tubes; inner steel tube and outer FRP tube, get a better ductile behavior of column, hybrid DSTCs prevent corrosion and buckling of inner steel tube because of concrete restrained steel tube absolutely that has increase rigidity of steel tube, prevent concrete from being crushed (steel tube benefit), protect columns from fire by warp column by outer FRP tube so that saving fire protection cost, vii. Higher capacity to support loading [4, 5, 6, 7]. Vincent et. al. (2013) [8], investigated the effect of confinement method on concrete specimens under axial compression load. Confinement method has no considerable influence on axial stress-strain behavior of FRP confined concrete and performance of FRP-wrapped concrete specimens have similar to CFFTs. Ozbakkaloglu el. at. 2014 [9], investigated seismic behavior of DSTC. This investigating leads to the concrete filled inner steel tube of DSTC improve high capacity of lateral drift, while the CFFT with hollow steel tube is less, DSTC may present an fascinating alternative open CFFT column in the earthquake-resistant of the building columns. Fanggi et. al. (2015)[10], presented the influence of inner steel tube cross section on square DSTC compressive behavior with or without concrete filled in steel tube. The DSTCs with circular hollow steel tube gave larger value of ultimate axial stress and strain compared with square hollow steel tube. Influence of the concrete inside steel tube as shown improves behavior of square DSTCs and similar in behavior of normal and high strength concrete filled inside steel tube and circular inner steel tube with same level of performance.

Ozbakkaloglu et. al. 2015 [11], investigated the DSTCs system with different grades of concrete, where filled concrete in between two tubes (FRP tube and steel tube) and inside steel tube, the study was leads to superior compression behavior of DSTCs, and behave very high load -deformation capacity. Farahi et. al. (2016) [12], presented the numerically on compressive behavior of steel tubular double skin filled with concrete, three generally types geometrically of cross-sections have conducted in this study, behavior of columns with concrete filled steel DSTC for given sections were generally like short column behavior. While much research has been conducted on the DSTCs with diameter $150 \mathrm{~mm}$ and height $300 \mathrm{~mm}$, the present study was aimed to investigating the compressive behavior of DST columns with dimension $100 \mathrm{~mm}$ and $310 \mathrm{~mm}$ to achieve properties of columns according to Building Code Requirements for Structural Concrete (ACI 318-05) [13]. The results of the experimental program are presented and followed by a discussions on the effect of the key parameters on the behavior of DSTCs and carbon FRP external tubes

\section{Experimental Program}

All 14 DSTCs have $100 \mathrm{~mm}$ in diameter and $310 \mathrm{~mm}$ in height, the outer FRP tubes have made by embedded carbon fiber sheet on polymer resin Table (1) illustrates details of specimens. The first letter of specimens name (D) refers to DSTC and (F) refers to CFFT.

The letter $(\mathrm{C})$ refer to concrete compressive strength of cubic fcu (70mm* 70mm) C60, C55, C50 and C45 MPa. The letters (ds) refer to diameter of inner steel tube diameter $48 \mathrm{~mm}$ ds 48 . The letters (ts) refer to thickness of inner steel tube thickness $1.5 \mathrm{~mm}$ ts 1.5 . The roman numeral (I) refer to number of carbon fiber reinforced polymer layers I: one layers. 
Table (1) Details of specimens

\begin{tabular}{|c|c|c|c|c|}
\hline Specimens Designation & $\begin{array}{c}\text { Cubic } \\
\text { Compressive } \\
\text { Strength of } \\
\text { Concrete }(\mathrm{MPa})\end{array}$ & $\begin{array}{c}\text { Diameter of } \\
\text { Inner Steel } \\
\text { Tube } \\
(\mathrm{mm})\end{array}$ & $\begin{array}{c}\text { Thickness of } \\
\text { Inner Steel } \\
\text { Tube (mm) }\end{array}$ & $\begin{array}{c}\text { Number of } \\
\text { Layers of FRP } \\
\text { Tube }\end{array}$ \\
\hline DC60ds48ts1.5I & 60 & 48 & 1.5 & 1 \\
\hline DC60ds48ts1.5II & 60 & 48 & 1.5 & 2 \\
\hline DC60ds48ts1.5III & 60 & 48 & 1.5 & 3 \\
\hline DC55ds48ts1.5I & 55 & 48 & 1.5 & 1 \\
\hline DC50ds48ts1.5I & 50 & 48 & 1.5 & 1 \\
\hline DC45ds48ts1.5I & 45 & 48 & 1.5 & 1 \\
\hline FC60I & 60 & Non & Non & 1 \\
\hline
\end{tabular}

\section{Material of DSTC}

\subsection{Concrete material}

The specimens have poured with high strength self-compact concrete (mortar) with four compressive strength and cement: sand 1:1.5 as shown details of mixes in Table

Table 2. Mortar mixes proportion

\begin{tabular}{|c|c|c|c|c|c|c|}
\hline $\begin{array}{c}\text { Mixes } \\
\text { Designation }\end{array}$ & $\begin{array}{c}\text { Water } \\
\text { /Cementatious }\end{array}$ & $\begin{array}{c}\text { Cement } \\
\text { :Sand }\end{array}$ & $\begin{array}{c}\text { Silica fume } \\
\text { \%from } \\
\text { weight of } \\
\text { cement }\end{array}$ & $\begin{array}{c}\text { S.P. \% from } \\
\text { weight of } \\
\text { cement }\end{array}$ & $\begin{array}{c}\text { Cubic } \\
\text { compressive } \\
\text { strength (fcu) } \\
\text { MPa }\end{array}$ & $\begin{array}{c}\text { Cylinder } \\
\text { compressive } \\
\text { strength (f́) } \\
\text { MPa }\end{array}$ \\
\hline C45 & 0.37 & $1: 1.5$ & 8 & 1.00 & 45 & 30 \\
\hline C50 & 0.36 & $1: 1.5$ & 10 & 1.36 & 50 & 35 \\
\hline C55 & 0.36 & $1: 1.5$ & 12 & 1.78 & 55 & 45 \\
\hline C60 & 0.35 & $1: 1.5$ & 15 & 2.17 & 60 & 50 \\
\hline
\end{tabular}

\subsection{Fiber Reinforced Polymer (FRP)}

Carbon fiber reinforced polymer tube (CFRP) was used in this work consists of two components, unidirectional carbon fiber sheet and epoxy resin. Table 3. illustrate the properties of carbon fiber sheet from data sheet. The carbon sheet has cut into three pieces, two small with 50 $\mathrm{mm}$ width and third pieces with $310 \mathrm{~mm}$ width, with overlapping zone $100 \mathrm{~mm}$, that pieces embedded with epoxy .

Table 3. Properties of carbon fiber

\begin{tabular}{|c|c|c|c|}
\hline $\begin{array}{c}\text { Nominal thickness } \\
\mathrm{tf}(\mathrm{mm}-\mathrm{ply})\end{array}$ & $\begin{array}{c}\text { Tensile } \\
\text { strength } \\
\mathrm{ff}(\mathrm{MPa})(\text { nominal })\end{array}$ & $\begin{array}{c}\text { Ultimate } \\
\text { tensile strain,6 } \\
\varepsilon \mathrm{f}(\%)\end{array}$ & $\begin{array}{c}\text { Elastic } \\
\text { modulus } \\
\mathrm{Ef}(\mathrm{GPa})(\text { nominal })\end{array}$ \\
\hline 0.12 & 4100 & 1.7 & 231000 \\
\hline
\end{tabular}

*from data sheet of carbon fiber.

\subsection{Steel Tubes}

Hollow steel tube (HST) is used in this study with ds 48 $\mathrm{mm}$ and ts $1.5 \mathrm{~mm}$, three specimens are tested under axial load to get properties steel tube, as show in Table 4. 
Table 4. Properties of steel tube

\begin{tabular}{|l|l|l|l|c|c|l|}
\hline Specimens & $\begin{array}{l}\text { Peak Load } \\
(\mathrm{kN})\end{array}$ & $\begin{array}{l}\text { Yield } \\
\text { Load } \\
(\mathrm{kN})\end{array}$ & $\begin{array}{l}\text { yieling } \\
\text { Stress } \\
(\mathrm{MPa})\end{array}$ & $\begin{array}{l}\text { Axial Strain } \\
(\mathrm{mm} / \mathrm{mm})\end{array}$ & $\begin{array}{c}\text { lateral Strain } \\
(\mathrm{mm} / \mathrm{mm})\end{array}$ & Modes Failure \\
\hline HSTds48ts1.5 & 75 & 60 & 327 & -1.550 & 2.034 & $\begin{array}{l}\text { global buckling, } \\
\text { elephant footing \& } \\
\text { rippling }\end{array}$ \\
\hline
\end{tabular}

* From compression test of steel tube in Diyala university, structural engineering lap.

\subsection{Instrumentation and Testing}

All specimens have tested under axial compression load until failure, the test conducted in university of Diyala, engineering college, structural lap. The testing machine with load capacity $2000 \mathrm{kN}$, the load increment was $1 \mathrm{kN} / \mathrm{sec}$, Figure 1. Shows set up of testing.

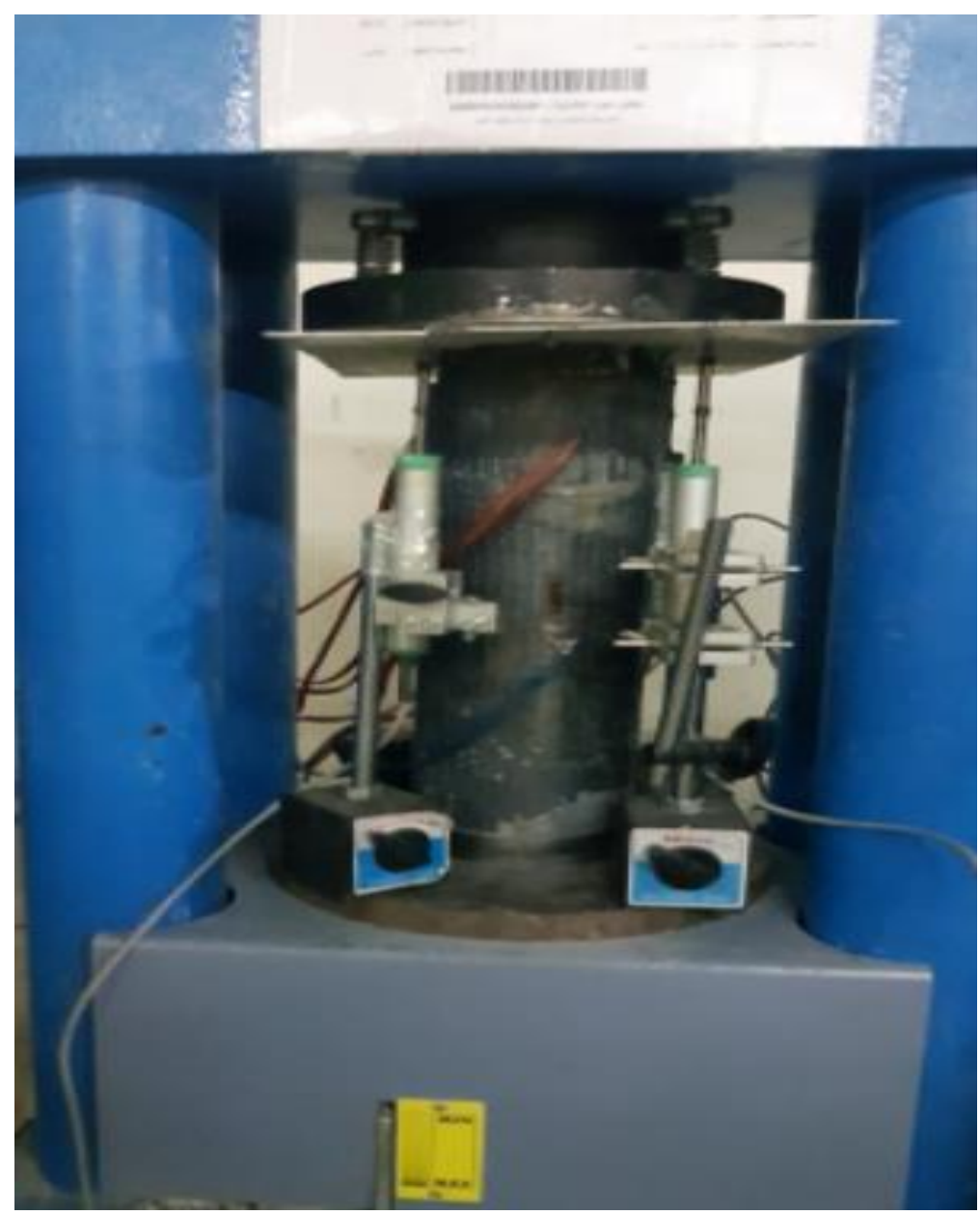

Fig 1. Set up of testing.

\section{Test Results and Discussion}

\subsection{Ultimate Load}

It can be seen that, better confinement by (two and three) layers of outer FRP tube in DSTCs which caused an increase in $\mathrm{Pu}$ by $(15 \%$ and $63 \%)$, respectively, compared with DSTC with one layer of FRP. When increased the compressive strength of concrete in DSTCs (50, 55 and 60) MPa caused increasing in value of $\mathrm{Pu}$ by
(5\%, 19\% and 32\%), respectively compared with DSTC of compressive strength of (45) MPa. While The Pu was increased in CFFT by (15\%) compared with DSTC. To evaluate the percentage between $(\mathrm{Pu})$ to assemblage of $(\mathrm{Pc})$ and $(\mathrm{Ps})$ ratio as called Load enhancement ratio (LE) as illustrated in eq. 1, (Yu, 2007 [14] and Ozbakkaloglu, 2013 [15] and ultimate load capacity of unconfined concrete $(\mathrm{Pc})$ has get from multiplying ultimate stress of unconfined concrete (fć) by cross section of concrete in side DSTC, and ultimate load of steel test (Ps) was 
ultimate load of steel tube get from compression test of steel tubes, (consider that ultimate load of DSTCs ignore effect of FRP confinement and combined part doesn't interact), the load enhancement ratio was given below:

$$
\mathrm{LE}=\frac{P u}{P c+P S}
$$

Load enhancement ratio gave a good indication of higher ultimate load with (15\% and 63\%) in DSTCs with two and three layers, respectively compared with DSTCs with one layers of FRP tube, consider exactly the same increasing in ultimate load and load enhancement ratio, that's because effective restrained concrete by two tubes, FRP tube outside and steel tube inside. In addition to number of outer FRP layers that provide more restriction.

Table 4. Summery of test result of specimens

\begin{tabular}{|c|c|c|c|c|c|c|c|c|c|c|c|c|}
\hline 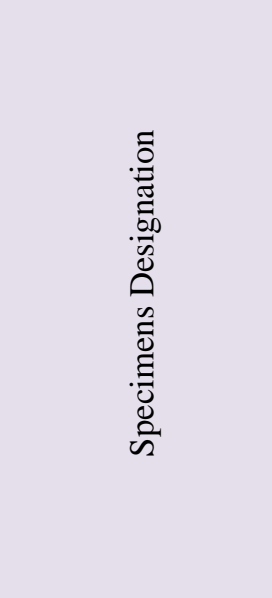 & 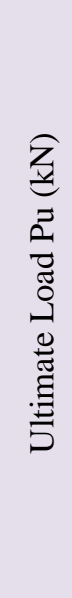 & 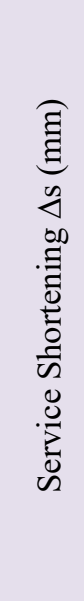 & 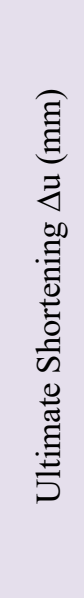 & 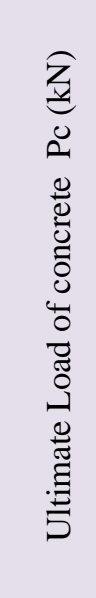 & 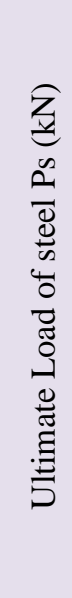 & 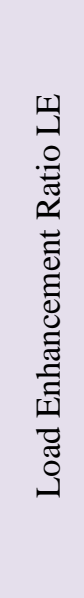 & 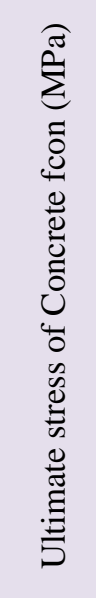 & 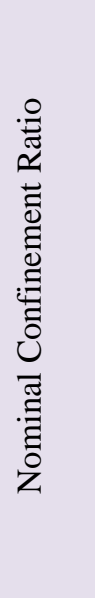 & 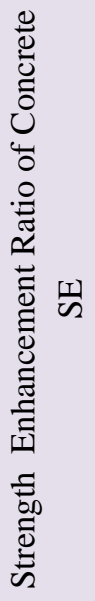 & 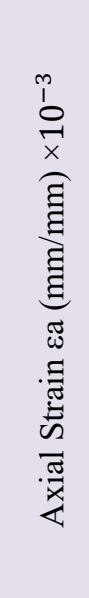 & 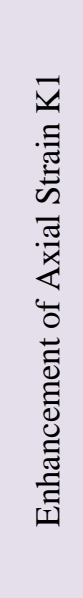 & 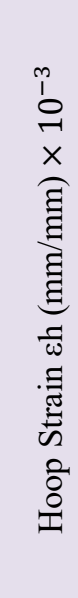 \\
\hline DC60ds48ts1.5I & 518 & 2.30 & 5.90 & 303.0 & 75 & 1.37 & 74.0 & 0.188 & 1.48 & -3.50 & 2.14 & 3.20 \\
\hline DC60ds48ts1.5II & 593 & 2.78 & 7.71 & 303 & 75 & 1.57 & 86.0 & 0.342 & 1.72 & -3.65 & 2.23 & 3.30 \\
\hline DC60ds48ts1.5III & 845 & 2.78 & 9.76 & 303 & 75 & 2.24 & 127.5 & 0.514 & 2.55 & -6.11 & 3.74 & 4.85 \\
\hline DC55ds48ts $1.5 \mathrm{I}$ & 460 & 2.70 & 5.70 & 272.3 & 75 & 1.32 & 63.6 & 0.209 & 1.41 & -3.42 & 2.57 & 3.23 \\
\hline DC50ds48ts1.5I & 414 & 2.70 & 5.54 & 242.0 & 75 & 1.31 & 55.5 & 0.235 & 1.40 & -3.41 & 2.64 & 3.50 \\
\hline DC45ds48ts1.5I & 393 & 2.80 & 5.40 & 212.0 & 75 & 1.36 & 53.5 & 0.269 & 1.50 & -3.10 & 3.15 & 3.70 \\
\hline FC60I & 595 & 1.80 & 7.14 & Non & Non & Non & 76 & 0.188 & 1.50 & -4.18 & 2.56 & 2.80 \\
\hline
\end{tabular}

\subsection{Load-Shortening Behavior}

The load-shortening relationship of specimens, the curve has bilinear at first part, after transition point at second part the curve became nonlinear and stiffer in specimens with (two and three) layers, the CFFT and specimens with C60 and one layers of outer FRP tube. The specimens of C55, C50 and C45 behave at the first part of the curve has bilinear, at the second part the ultimate shortening was increase with load increase, after bilinear first part drop in load has occur in curve because of redistribution stress after yielding of inner steel tube, as shows in Figure 2, 3 and 4 below. From Table 4. it can be seen that the service shortening $\Delta \mathrm{s}$ (at the service stage was considered by $70 \%$ of reference ultimate load Ibrahim et al, 2013) [16], $\Delta$ s has slightly decreased, while the ultimate shortening was increased by $(24 \%$ and $54 \%$ ) in DSTCs with two and three layers of outer FRP tube respectively compared with specimens DSTC with one layers of FRP tube as shown in Figure 2., the similar observation with (Yu et. al, 2013) increase number of FRP layers caused increasing in the ultimate load and ultimate shortening.

The service shortening decreased by $(4 \%, 18 \%$ and $18 \%)$, and ultimate shortening has increased by $(2.6 \%, 5.5 \%$ and $9.2 \%)$ in DSTCs with compressive strength $(50,55$ and 60) $\mathrm{MPa}$, respectively, compared with DSTCs with compressive strength (45) as show in figures 3 .

The service shortening was decrease by (18\%), and ultimate shortening was increase by $(21 \%)$ in CFFT compared with DSTC, the ultimate shortening of CFFT was more than DSTC because of CFFT restrained by outer FRP tube only, while DSTC has restrained by two tubes outer FRP tube and inner steel tube inside as shown in figure 4. 


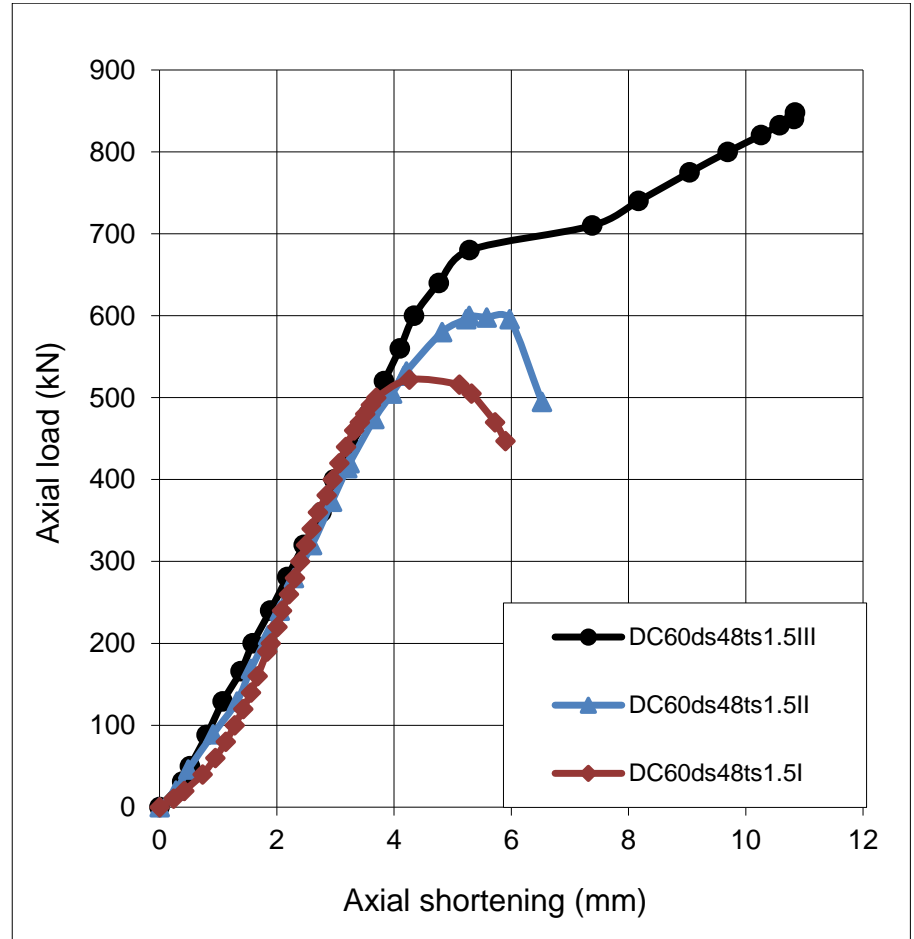

Fig 2. Load- shortening relationship of DSTCs with (one, two and three) layers of FRP tube.

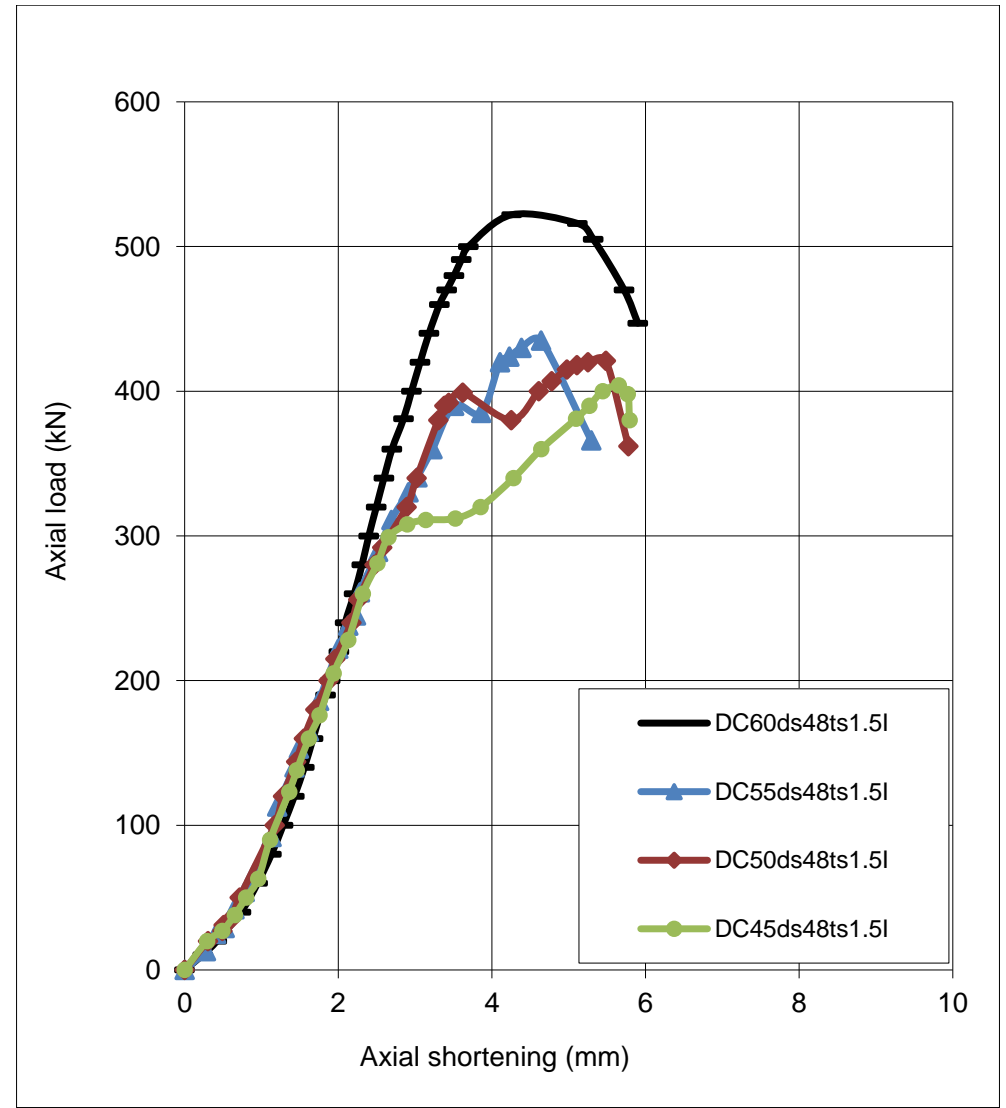

Fig 3. Load- shortening relationship of DSTCs compressive strength (45, 50, 55 and 60) MPa layers of FRP tube. 


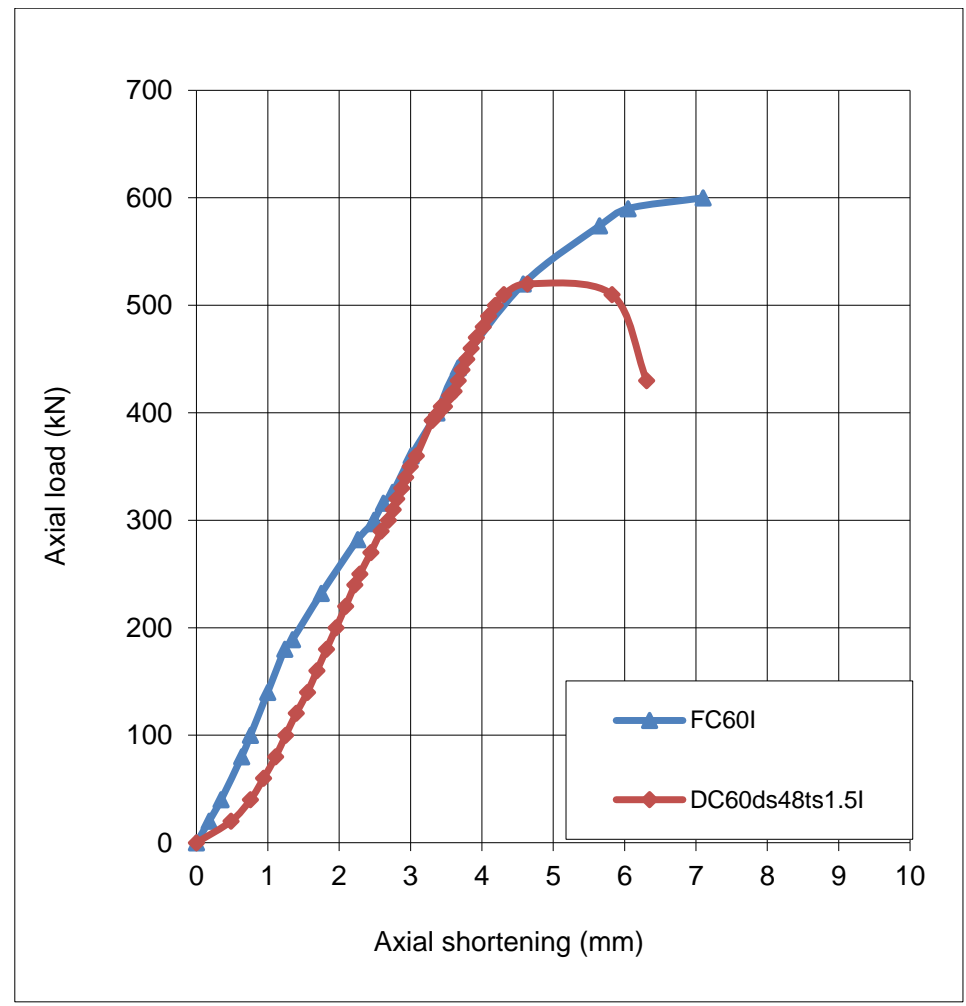

Fig 4. Load- shortening relationship of DSTCs and CFFT.

\subsection{Stress- Strain Behavior}

The confinement of concrete has became very necessary to increase compressive strength and protect concrete from weathering condition. Therefore; behavior of concrete in DSTC should be investigated, for the designing of outer FRP tube the nominal confinement ratio has percentage between confining pressure to concrete compressive strength, calculated from Eq. 2 to assuming a uniform confinement distribution, as the performance criterion in establishing relative confinement levels of DSTCs with different concrete strengths (Ozbakkaloglu et. al., 2013)

$\frac{\mathrm{f}_{1}}{\mathrm{fć}^{\prime}}=\frac{2 \mathrm{t}_{\mathrm{f}} \mathrm{E}_{\mathrm{f}} \varepsilon_{\mathrm{f}}}{D_{\mathrm{f}} \mathrm{fć}}$

Where :

$\mathrm{f}_{1}$ : confining pressure $(\mathrm{MPa})$. fć: cylinder concrete compressive strength $(\mathrm{MPa})$.

$E_{\mathrm{f}}$ : modulus of elasticity of FRP (GPa).

$\mathrm{t}_{\mathrm{f}}$ : total nominal thickness of $\mathrm{FRP}(\mathrm{mm})$

\&f : ultimate tensile strain of the fibers $(\mathrm{mm} / \mathrm{mm})$.

$D_{\mathrm{f}}$ : internal diameter of the FRP tube $(\mathrm{mm})$.

Nominal confinement ratio were increased by $(82 \%$ and $172 \%$ ) in DSTCs with two and three layers of outer FRP tube as illustrate in Table 4., that's increasing in nominal confinement ratio leads to more effect of FRP tube layers and increasing in axial load and ultimate shortening. The stress-strain curve of concrete inside DSTCs of specimens with one, two and three layers are illustrate in Figures 5. to 7 . respectively. 


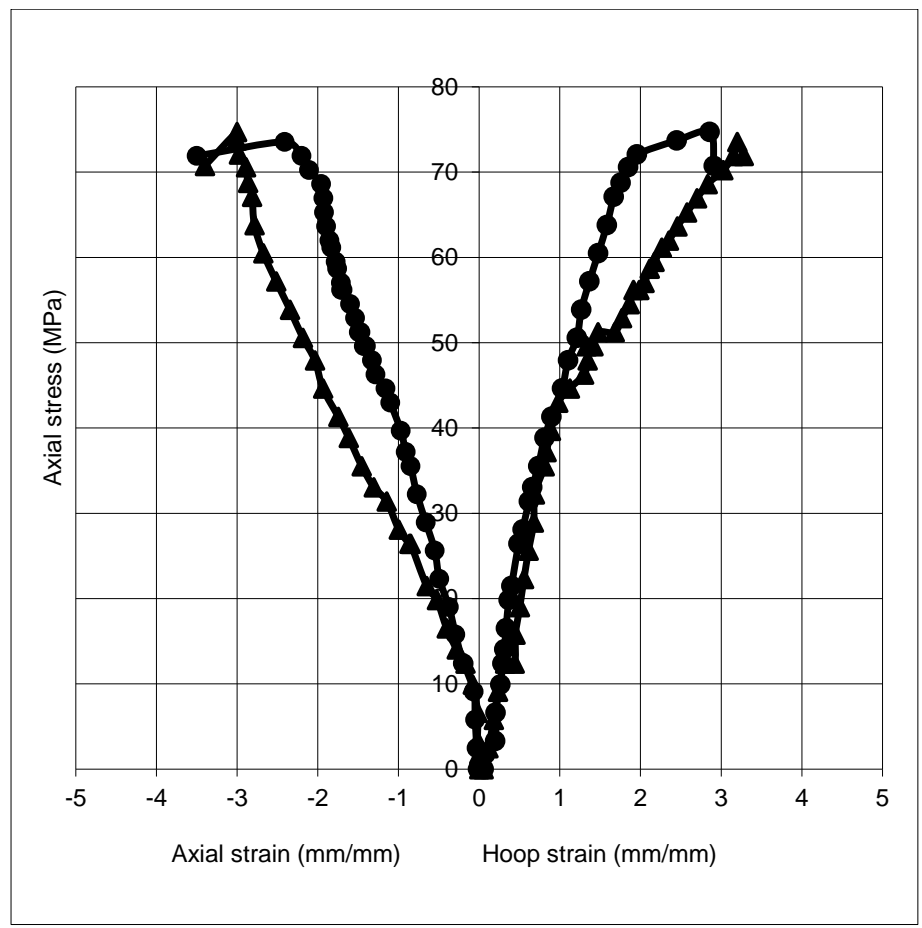

Fig 5. Stress-strain relationship of specimen DC60ds48ts1.5I.

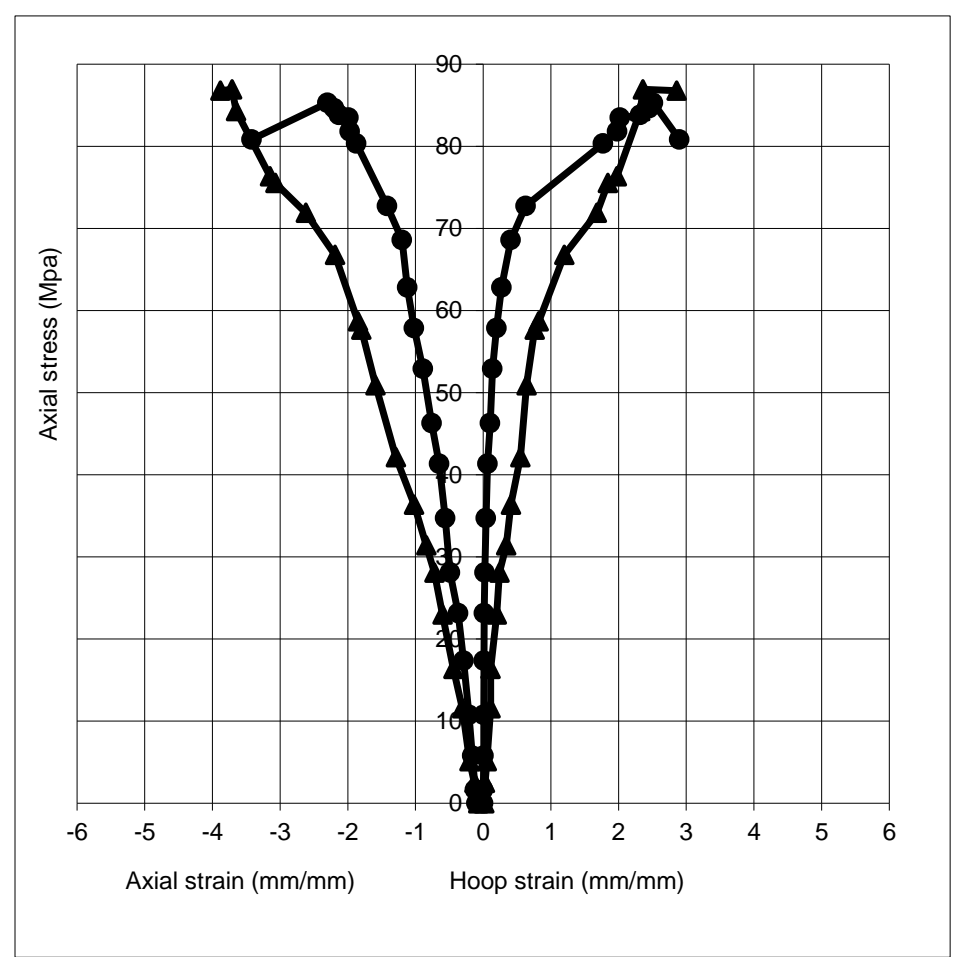

Fig 6. Stress-strain relationship of specimen DC60ds48ts1.5II. 


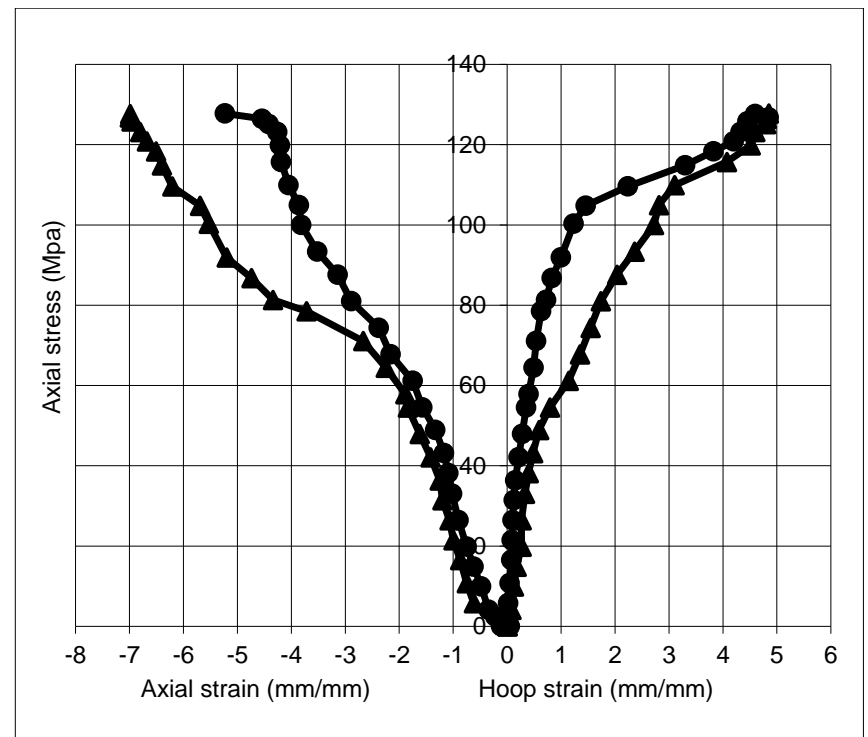

Fig 7. Stress-strain relationship of specimen DC60ds48ts1.5III.

The stress of concrete inside DSTC (fcon) evaluated by ultimate load of DSTC subtraction from ultimate load of steel tube test to same strain, fcon have increased by $(16 \%$ and $72 \%$ ) in DSTCs with two and three layers. The strength enhancement ratio of concrete inside DSTC (SE) (get from dividing the ultimate stress of confinement concrete to ultimate strength of unconfinement concrete), SE ratio has increased significantly the same increasing of concrete stress.

The axial strain of concrete in DSTC has gotten from average of two strain gauges at mid height of specimens. Enhancement of axial strain (K1) has gotten from divided axial strain of confined column ( $\varepsilon a)$ to the axial strain of unconfined concrete ( $\varepsilon \mathrm{co}$ ) (from cylinder 100*200 $\mathrm{mm}^{2}$ ),
$\mathrm{K} 1$ increased by (4\% and 74\%) in DSTC with two and three layers of FRP, that's due to the amount of confinement leads to better ductility and strength of concrete inside DSTCs.

Nominal confinement ratio has decreased by $(13 \%, 22 \%$ and 30\%) in DSTCs with compressive strength $(50,55$ and 60) MPa compared with DSTC of compressive strength of (45) MPa, that's leads to the confinement of concrete became very effective, Especially, when compressive strength of concrete has low. The stressstrain relationship of DSTCs with compressive strength (55, 50 and 45) $\mathrm{MPa}$ show in Figures 8, 9 and 10 respectively, it can be seen that the drop in curve occur after inner steel tube reach to yielding stage.

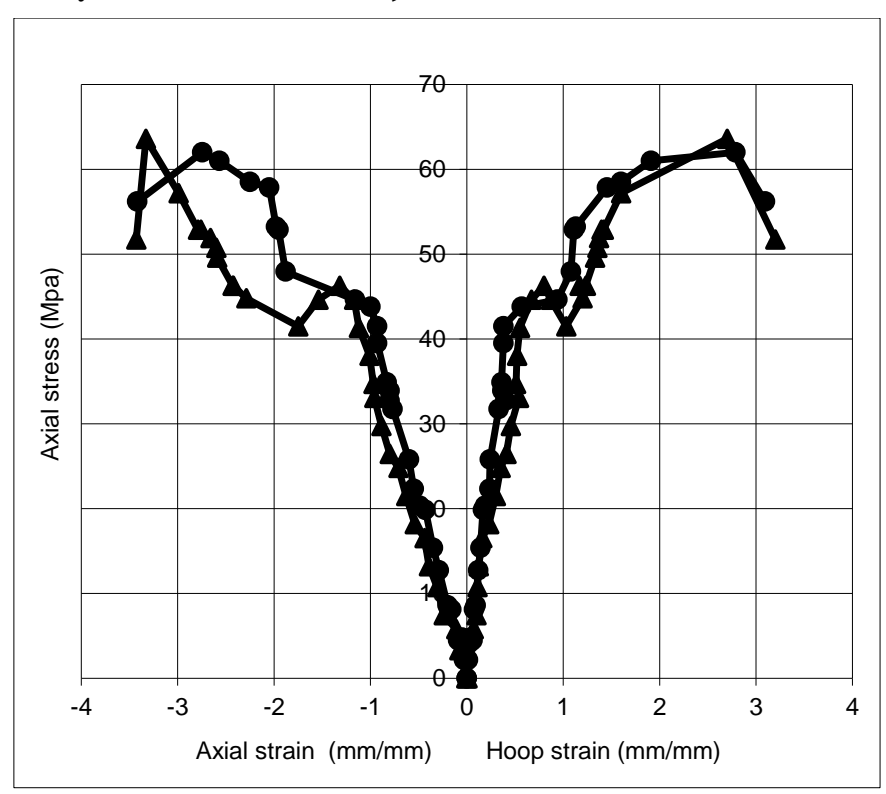

Fig8. Stress-strain relationship of specimens DC55ds48ts1.5I. 
Diyala Journal of Engineering Sciences Vol. 13, No. 01, March 2020, pages 106 -117

ISSN 1999-8716

DUI: $10.24237 /$ djes.2020.13112

eISSN 2616-6909

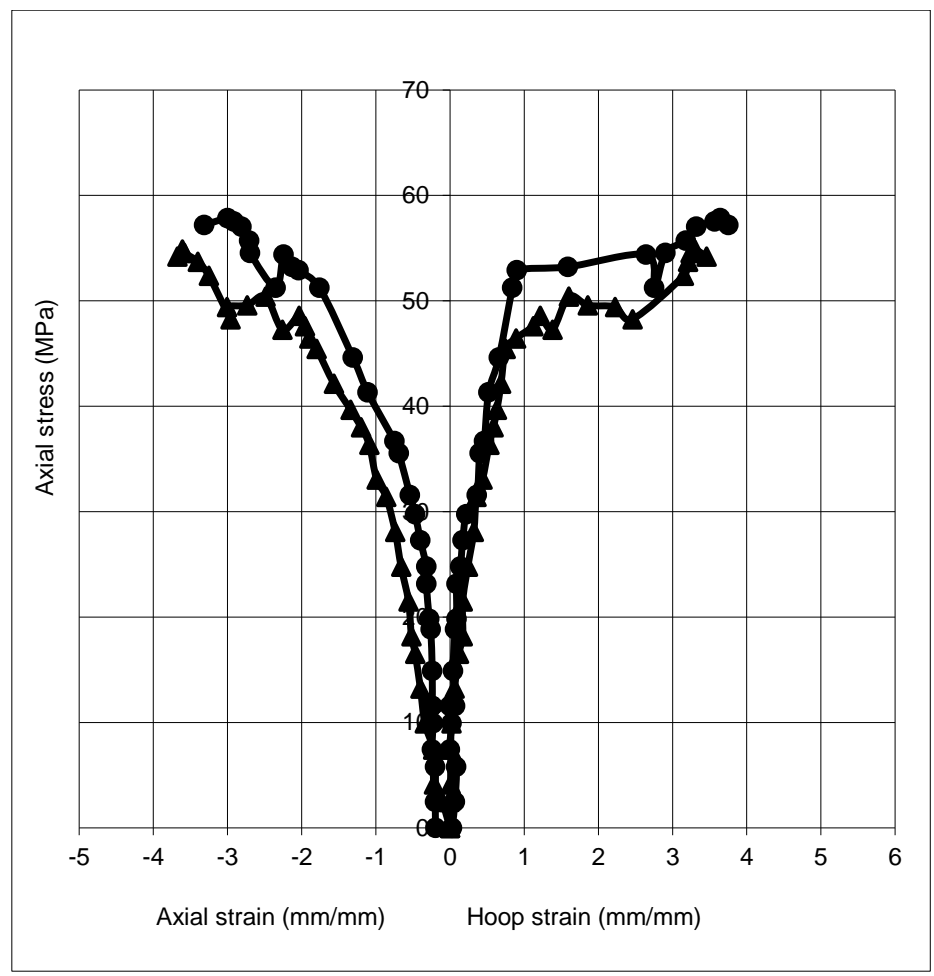

Fig 9. Stress -strain relationship of specimens DC50ds48ts1.5I.

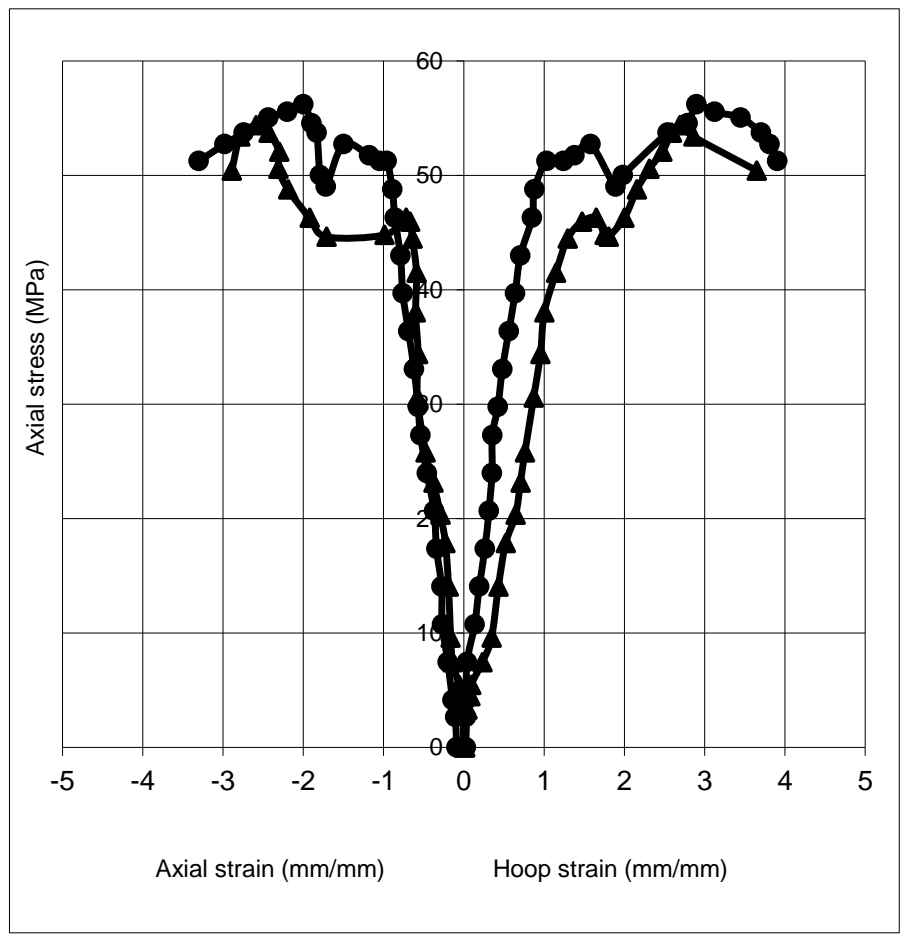

Fig 10. Stress -strain relationship of specimens DC45ds48ts $1.5 \mathrm{I}$.

Stress of concrete inside DSTCs (fcon) has increased by $(5 \%, 19 \%$ and $38 \%)$ in specimens with compressive strength (50, 55 and 60) Pa respectively, the strength enhancement ratio has high value in DSTCs with compressive strength of concrete (45) MPa compared with the other specimens in this group that's leads to strength of concrete did not clearly effect on SE.
The enhancement of axial strain (K1) was decrease by (16\%, 18\% and 32\%) with increased compressive strength of concrete in DSTC (50, 55, and 60) IPa, respectively, that's because concrete inside DSTCs subjected to restrained from two tubes to raised its strength in addition to its strength. Nominal confinement ratio of CFFT and DSTC for designing outer FRP tube has the same because the ratio depends on inner diameter

114 
of FRP tube and concrete compressive strength. The concrete filled FRP tube column was confined effectively outward and ultimate stress of concrete inside CFFT was calculated by divided ultimate load by annular area of concrete, by comparison between stress- strain relationship of DSTC and CFFT, the CFFT has superior in its behavior, both of columns had bilinear stress-strain relationship as show in Figure 11. The strength enhancement ratio was approximately more in CFFT than DSTC as by (1.3\%). The enhancement of axial strain had a large value in CFFT with value because of axial strain of CFFT more than DSTC by (19\%), that's because of presence of inner steel tube.

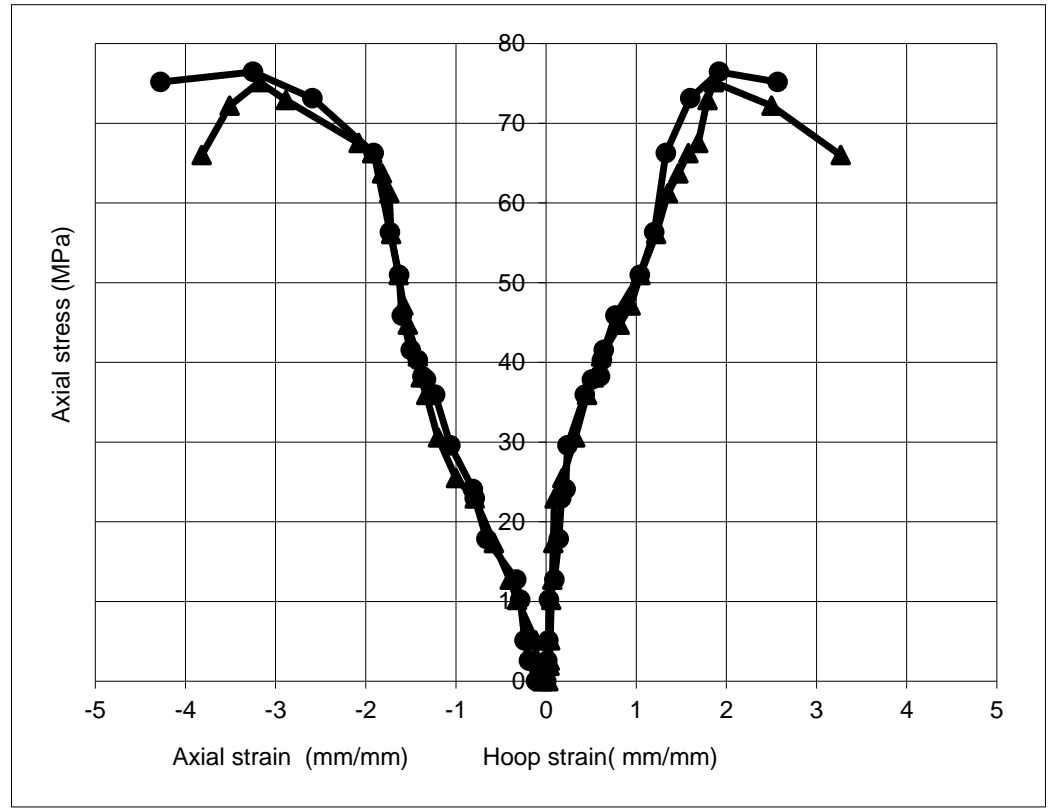

Figure 11. Stress-strain relationship of specimens FC60I.

\subsection{The Hoop Strain}

The hoop strain of FRP tube in DSTCs ( $\varepsilon$ h) has obtained from average of three strain gauges distribution along overlap region, the $\mathrm{ch}$ increased by $(3.1 \%$ and $51 \%)$ in DSTCs with two and three layers, respectively compared with DSTCs of one layer, as illustrate in Table 4. . The ch decreased by $(5 \%, 13 \%$ and $14 \%)$ in DSTCs with concrete compressive strength of $(50,55$ and 60) $\mathrm{MPa}$, respectively compared with DSTCs of concrete compressive strength of (45) MPa.

The ch in CFFT less than DSTC because large amount of concrete confinement by FRP tube and inner steel tube.

Experimental reduction factor of hoop strain $\mathrm{K} \varepsilon$ ex. was calculated from (Xie et. al., 2015)[17] :

$$
\mathrm{K} \varepsilon \text { ex. }=\frac{\varepsilon h}{\varepsilon f}
$$

Where \&f : the tensile strain of carbon fiber. And theoretical redaction factor of hoop rupture of FRP Ke th. was calculated from (Xie el. al., 2015) :
$\mathrm{K} \varepsilon$ th $=0.9-2.3 \mathrm{fc} \times 10^{-3}-0.75 \mathrm{Ef} \times 10^{-6}$

Where fć unconfined concrete compressive

strength and Ef the modulus of elasticity, the

value of $\mathrm{K} \varepsilon$ th (0.78) less than $\mathrm{K} \varepsilon$ ex. (1.64\%).

\subsection{Modes Failure of Specimens}

The specimens DC60ds48ts1.5II, DC60ds48ts1.5III have failed by rupture of outer carbon FRP tube at top height because of concrete movement as a result of higher load, while the specimens (DC60ds48ts1.5I, DC55ds48ts1.5I, DC50ds48ts1.5I and DC45ds48ts1.5I) failed by hoop rupture at mid height of outer carbon FRP tube, the specimens FC60I failed by rupture of hoop tension outer FRP tube and failure accompanied with spalling of concrete out ward and very high sound, while failure of concrete in DSTC was less spalling. As show in Figure 12. 


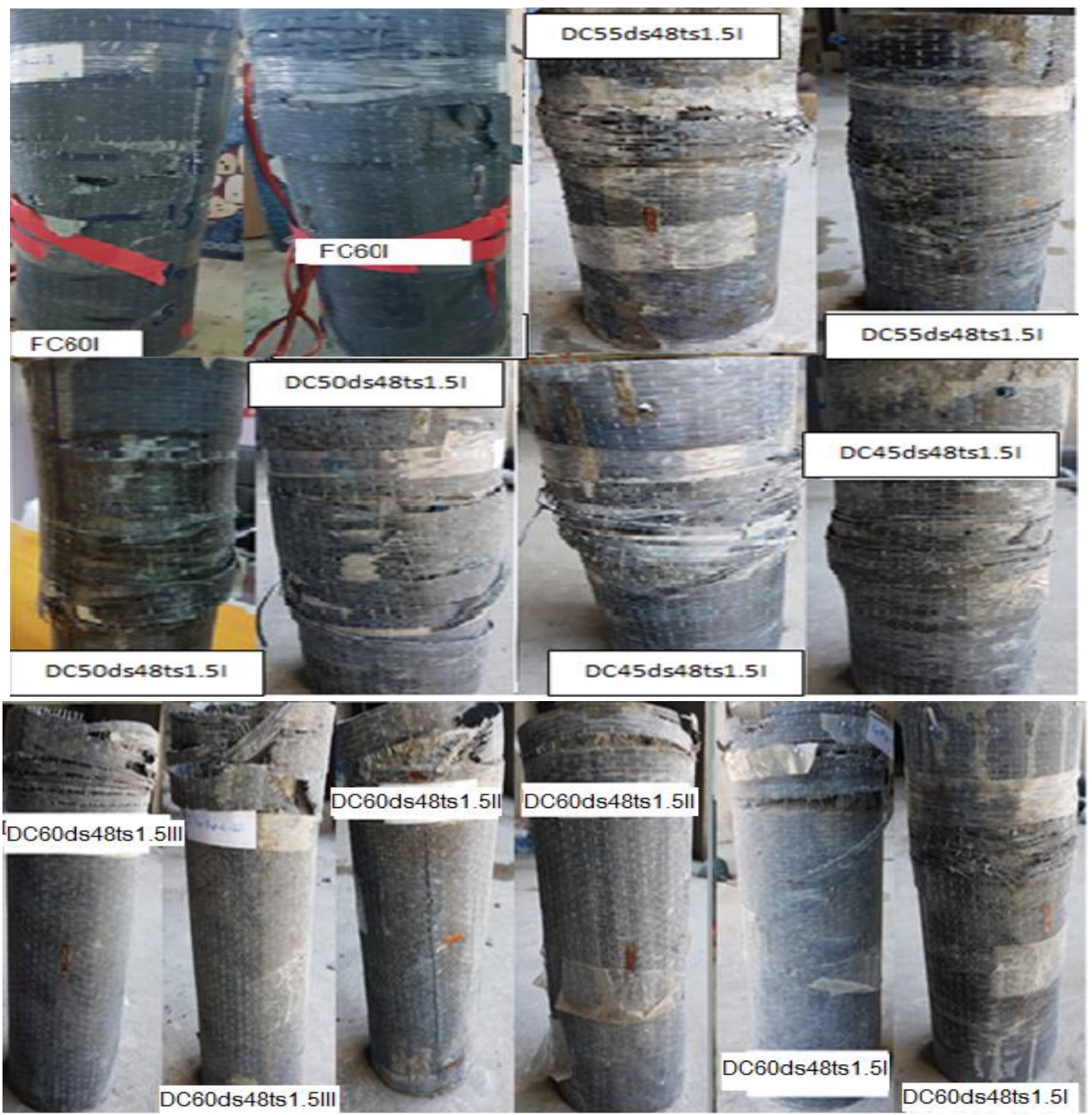

Fig 12. Modes failure of specimens.

\section{Conclusion}

1- The concrete effectively confinement between two tubes FRP outward and steel tube inward, leads to increases strength and ductility of columns.

2- Outer FRP tube prevent spalling of concrete and number of FRP tube layers were most effected parameters, when increased number layers of FRP tube from (one to two and three) strength enhancement ratio increased by (16\% and $72 \%)$, enhancement of axial strain increased by ( $4 \%$ and $74 \%)$.

3- When increased compressive strength of concrete from (45 to 50, 55 and 60) $\mathrm{MPa}$, slightly effected on strength enhancement ratio, enhancement of axial strain was decrease by (16\% to $32 \%)$.

4- The CFFT has more than DSTC in ultimate load, because of a large amount of concrete confinement.

\section{Acknowledgment:}

This work was supported by Diyala University, Civil Engineering Department, Structural Engineering Lap., which is gratefully acknowledged

\section{Reference}

[1] Ozbakkaloglu, T. and Vincent, T., 2013. Axial compressive behavior of circular high-strength concretefilled FRP tubes.Journal of Composites for Construction, 18(2), p.04013037.

[2] Fanggi, L., Alfonsius, B. and Ozbakkaloglu, T., 2014. Influence of concrete-filling inner steel tube on compressive behavior of double-skin tubular columns. In Advanced Materials Research (Vol. 838, pp. 535-539). Trans Tech Publications.

[3] Salman WD, Mansor AA, Mahmood M., 2018. Behavior of Reinforced Concrete One-Way Slabs Strengthened by CFRP sheets in Flexural Zone. International Journal of Civil Engineering and Technology (IJCIET) Volume.;9, pp.1872-81.

[4] Yu, T. and Teng, J.G., 2012. Behavior of hybrid FRPconcrete-steel double-skin tubular columns with a square outer tube and a circular inner tube subjected to axial compression. Journal of composites for construction, 17(2), pp.271-279. 
[5] Yu, T. and Remennikov, A.M., 2013. Hybrid doubleskin tubular members for sustainable mining infrastructure.

[6] Teng, J.G., Yu, T., Wong, Y.L. and Dong, S.L., 2007. Hybrid FRP-concrete-steel tubular columns: concept and behavior. Construction and building materials, 21(4), pp.846-854.

[7] Wissam D. Salman, 2015. STRENGTH AND BEHAVIOR OF COMPOSITE STEEL TUBE CONCRETE BEAM. Diyala Journal of Engineering Sciences, Vol. 08, No. 02, pp. 163-181.

[8] Vincent, T. and Ozbakkloglu, T., 2013. The effect of confinement method and specimen end condition on behavior of FRP-confined concrete under concentric compression. In Applied Mechanics and Materials (Vol. 351, pp. 650-653). Trans Tech Publications.

[9] Ozbakkaloglu, T. and Idris, Y., 2014. Seismic behavior of FRP-high-strength concrete-steel double-skin tubular columns. Journal of Structural Engineering, 140(6), p.04014019.

[10] Fanggi, L., Alfonsius, B. and Ozbakkloglu, T., 2015. Effect of Inner Steel Tube Cross-Sectional Shape on Compressive Behavior of Square FRP-Concrete-Steel Double-Skin Tubular Columns. In Applied Mechanics and Materials (Vol. 752, pp. 578-583). Trans Tech Publications.

[11] Ozbakkaloglu, T., 2015. A novel FRP-dual-grade concrete-steel composite column system. Thin-Walled Structures, 96, pp.295-306.

[12] Farahi, M., Heidarpour, A., Zhao, X.L. and AlMahaidi, R., 2016. Compressive behaviour of concretefilled double-skin sections consisting of corrugated plates. Engineering Structures, 111, pp.467-477.

[13] ACI Committee, 2005. Building code requirements for structural concrete (ACI 318-05) and commentary (ACI 318R-05). American Concrete Institute.

[14] Yu, T., Wong, Y.L., Teng, J.G. and Dong, S.L., 2007. Structural behavior of hybrid FRP-concrete-steel double-skin tubular columns (Vol. 68, No. 05).

[15] Ozbakkaloglu, T. and Fanggi, B.L., 2013. Axial compressive behavior of FRP-concrete-steel double-skin tubular columns made of normal-and high-strength concrete. Journal of Composites for Construction, 18(1), p.04013027.

[16] Ibrahim, A.M., Oukaili, N.K.A. and Salman, W.D., 2013. FLEXURAL CAPACITIES OF REINFORCED CONCRETE TWO-WAY BUBBLEDECK SLABS OF PLASTIC SPHERICAL VOIDS. Diyala Journal of Engineering Sciences, Vol. 06, No. 02, pp. 9-20
[17] Xie, T. and Ozbakkaloglu, T., 2015. Behavior of steel fiber-reinforced high-strength concrete-filled FRP tube columns under axial compression. Engineering Structures, 90, pp.158-171. 